\title{
LA EDUCACIÓN DE LAS ÉLITES EFESIAS *
}

MARÍA PAZ DE HOZ

Universidad de Salamanca

El objetivo de este trabajo es estudiar la epigrafía helenística e imperial de Éfeso sobre la institución educativa, analizando sobre todo los siguientes aspectos: etapas de la educación, centros de enseñanza, profesores, otros cargos relacionados con la educación, actividades sociales como fiestas y agones que indirectamente reflejan distintas facetas de la enseñanza, las instituciones del Museo y la biblioteca de Celso. El estudio refleja el alto grado de implicación pública en la educación de los jóvenes, al menos de las clases superiores, y una preocupación especial de la ciudad por la cultura, a diferencia de lo que la ausencia de información literaria sobre el tema y los testimonios epigráficos aislados han llevado a pensar.

Palabras-clave: educación griega, gymnásion, cultura, instituciones, epigrafía, Asia Menor, Éfeso

Casi todos los estudios modernos sobre la educación en la antigüedad griega basados en fuentes epigráficas están dedicados a la época helenística,

* Este trabajo forma parte del proyecto de investigación Influencia de la escuela en Grecia: Textos literarios, papirológicos y epigráficos, financiado por la DGICYT (BFF 2002-1957). En una versión abreviada fue expuesto en el XII Congreso Internacional de Epigrafía Griega y Latina celebrado en Barcelona en septiembre del 2002. Los números de inscripción sin ninguna indicación hacen referencia a H. Wankel, Ch. Börker, R. Merkelbach, H. Engelmann, D. Knibbe, R. Meric, S. Sahin y J. Nollé (edd.), Die Inschriften von Ephesos (Inschriften Griechischer Städten Kleinasiens $\mathrm{n}^{\circ}$ 11-17), Bonn, 1979-84. Las abreviaturas de corpora epigráficos son las utilizadas en F. Rodríguez Adrados et al., Diccionario Griego-Español, Madrid 1989-.

EMERITA. Revista de Lingüística y Filología Clásica (EM) — LXXII 1, 2004 
y no es de extrañar, puesto que a ésta pertenecen los textos más llamativos, que proporcionan valiosa información sobre los maestros, salarios, asignaturas etc., como las fundaciones de Eudemo de Mileto o Politro de Teos, la ley gimnasiástica de Berea, o algunas listas de vencedores en las غ̇ं pruebas escolares.

Los testimonios para la educación en las grandes ciudades del oriente romano resultan mucho más parcos en comparación. Sin embargo, un estudio conjunto de la información sobre este aspecto a través de las fuentes epigráficas puede revelar un panorama muy diferente del que se obtiene a primera vista, y ser precisamente la escasez y dispersión de la información indicio de una base educativa bastante sólida. Para obtener conclusiones fiables y una visión general coherente del panorama educativo imperial es necesario estudiar en conjunto el material epigráfico sobre este tema en las distintas ciudades y Éfeso es, por su calidad de metropolis y capital de Asia, y por la gran cantidad de material epigráfico que ha proporcionado, una buena ciudad para empezar un estudio sistemático.

En la Éfeso del s. II d.C., época de la que data la mayor parte de la información epigráfica, vivió el joven Habrócomes, protagonista de la novela de Jenofonte de Éfeso Las Efesiacas. Cuando comenzaron sus aventuras era un efebo de unos 16 años, y un efebo sobresaliente en el que «florecían la belleza absoluta del cuerpo y todas las virtudes del alma, pues se ejercitaba en todo tipo de educación y practicaba las más variadas artes» (I 1.2). No sabemos nada de la educación que debió recibir Habrócomes en su tierna infancia, posiblemente privada en su casa, ya que pertenecía a una familia distinguida, pero sin duda en algún momento entre los 7 y 14 años empezó la enseñanza secundaria en la categoría de $\pi \alpha \tilde{i} \varsigma^{1}$. No hay ningún testimonio de escuelas públicas en las que se impartiera esta enseñanza y es muy probable

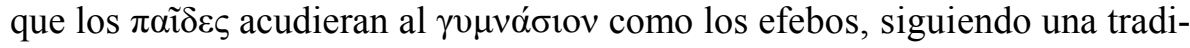

1 Cf. M.P. Nilsson (Die hellenistische Schule, Munich 1955, pág. 34ss.) para la idea de que la efebía empezaba entre los griegos a los 15 años, con el comienzo de la pubertad, y no a los 18 como establece H.I. Marrou (Historia de la educación en la antigüedad, Madrid 1985 (trad. del francés de 1971), pág.138s.) basándose en la efebía ateniense. Aparte de este testimonio de Jenofonte de Éfeso en sus Efesíacas, una inscripción funeraria de Esmirna (ISmyrna 552), del s. I d.C., dedicada a un joven de 16 años que acaba de pasar a la categoría de efebo, confirma la idea de Nilsson para Asia Menor imperial. Cf Pleket, Mnemosyne 39 (1986), pág. 555 para la suposición de que la baja edad de los efebos en las ciudades helenísticas y romanas se deba a la participación cada vez más temprana de los hijos de la élite urbana en la política ciudadana. 
ción atestiguada en el s. II a.C., donde la dedicación a [Hermes], Heracles y el rey Eumenes II de una lista de vencedores en pruebas escolares de $\pi \alpha \tilde{i} \delta \varepsilon \varsigma$

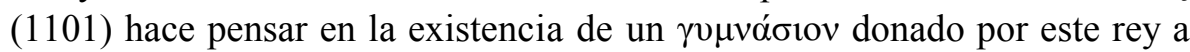
Éfeso, como hizo por ejemplo en Mileto $^{2}$. Habrócomes seguramente asistió

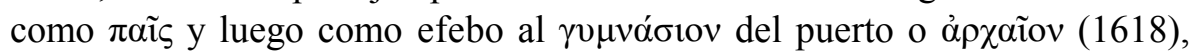
con sus termas, palestra y la gran $\pi \varepsilon \rho 1 \delta \rho o \mu$ í rodeada de una colonada ( $\xi v \sigma-$

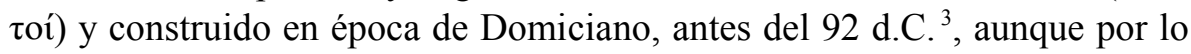

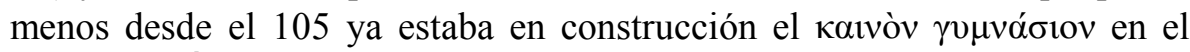

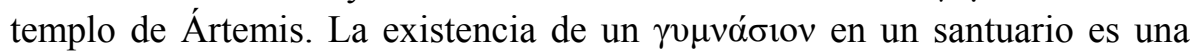
novedad y hasta hace poco el Kaıvóv (3066, del 105 d.C.) se identificaba con

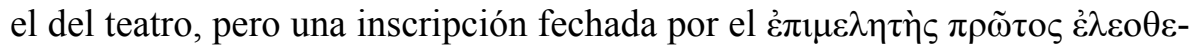

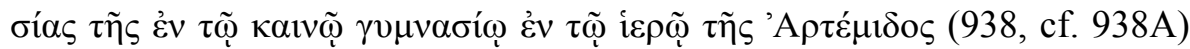
parece no dejar lugar a dudas ${ }^{4}$. Los niños de finales del siglo tenían muchas más posibilidades, pues la expansión constructiva tan bien conocida en las ciudades minorasiáticas del s. II había llevado a la existencia por lo menos de tres $\gamma v \mu v \alpha ́ \sigma 1 \alpha$ más: el de Vedio o $\sigma \varepsilon \beta \alpha \sigma \tau o ́ v ~(633,661)$, junto al estadio, construido en época de Antonino Pío ${ }^{5}$; el oriental, situado junto a la puerta de Magnesia y donado por el sofista Damiano; y el del teatro, ambos de finales del siglo ${ }^{6}$. Lo que no sabemos es si los $\pi \alpha \tilde{i} \delta \varepsilon \varsigma$ y efebos podían

2 El rey Eumenes aparece a menudo asociado con los dioses del gymnásion, como es frecuente entre los soberanos helenísticos (v. L. Robert, Bull.Épigr. 1953, n 178). Para las fuentes literarias que atestiguan la existencia de un gymnásion helenístico en Éfeso (Jenofonte [Hell. III 4.16-18] habla de gymnásia en plural refiriéndose al 395 a.C.), v. J. Delorme, Gymnasion. Étude sur les Monuments consacrés a l'éducation en Grèce, París 1960, pp. 337-61.

3 Una inscripción (1128) fechada en este año gracias a la mención del cónsul atestigua

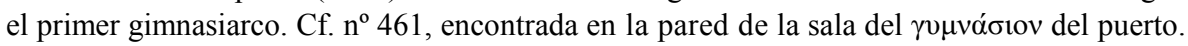
Probablemente en este gimnasio estaba hablando Apolonio de Tiana a la ciudad de Éfeso cuando tuvo la visión del asesinato de Domiciano en el 96 d.C. (Philostr., VA 8.26).

4 v. E. Fontani «La Gimnasiarchia perpetua di Artemide a Efeso», en H. Frisinger- KF. Krinzinger (edd.), Akten des Symposions 100 Jahre österreichische Forschungen in Ephesos, Wien 1995, Viena 1999, págs. 263-7. Cf. infra. pp. 28-29.

5 Para la identificación del gimnasio con el Sebastón cf. Malalas (p. 200 Bonn), según el cual Antonino Pío construyó los baños en distintas ciudades de Asia Menor, entre ellas Éfeso de Asia, y les puso su nombre.

${ }^{6} \mathrm{Al}$ sur de las termas de Vario podría haber existido una palestra, lo que convertiría

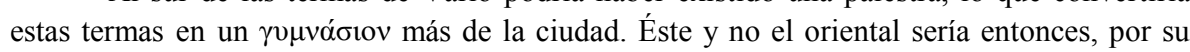

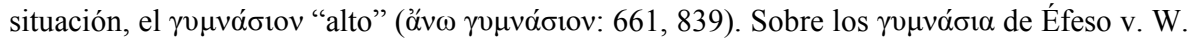
Alzinger, RE, Suppl. XII (1970), 1607-19; Fontani, ob. cit., sobre el del templo; M. SteskalM. La Torre, ÖJh 70, 2001, pp. 221-244. sobre el de Vedio. 
realmente elegir entre todos ellos para recibir su educación, o si existía una distribución según edades, como parece que se da en otras ciudades, y sólo la existencia de un gimnasiarco de los véor $(6,1102$, ambos de época hele-

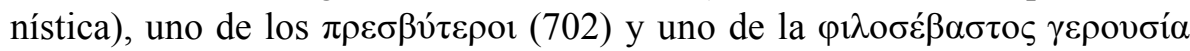
(442, 1587; ÖJh. 62, 1993, p. 116s., no 8 y 9) podría, aunque no necesariamente en los dos últimos tipos dado el carácter principalmente litúrgico de este cargo en época imperial, estar relacionada con $\gamma v \mu \nu \alpha \dot{\sigma} \alpha \alpha$ especiales para $\pi \rho \varepsilon \sigma \beta v ́ \tau \varepsilon \rho o \imath$ y véor ${ }^{7}$. Cuando se especifica la función del gimnasiarco se trata casi siempre del suministro de aceite ( $\dot{\varepsilon} \lambda \alpha 10 \theta \varepsilon \sigma i ́ \alpha)$, y en algún caso de

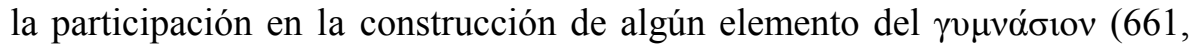
3066) o la financiación de espectáculos (702). Sólo en los dos testimonios

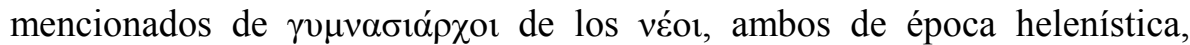
podemos suponer una función realmente educativa de este cargo, sobre todo en el caso de Diodoro Mentoros (6), que recibe una dedicación honorífica en

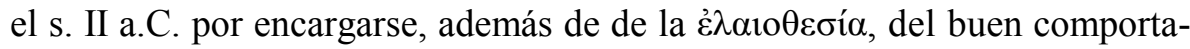
miento de los véol, de su sentido del respeto y humildad y de su buena condición física y mental, y de prepararles para adquirir la fama y gloria

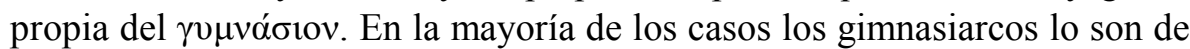

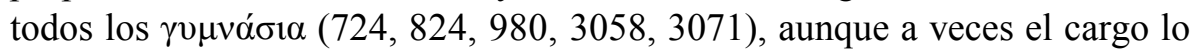
desempeñen en relación con alguna fiesta concreta (924A: las Megala Artemisia, 661: el día de la Katagogia; 644: el día de Androclo) o visita del emperador (728: durante los días de la visita del emperador Lucio Aurelio Vero en Éfeso en el 164 y 166 d.C.).

La gimnasiarquía perpetua nació, según atestigua la numismática, como

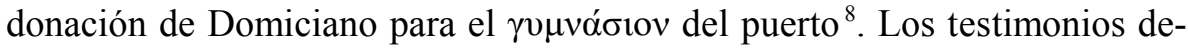
muestran que en general era el Artemision el que sufragaba los gastos de esta gimnasiarquía y que ésta estaba relacionada, al menos en algunos casos,

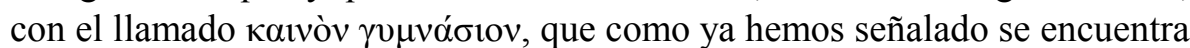
en el templo según una inscripción ${ }^{9}$. Pero existen ciertos problemas de difí

7 Para n 702 y 1587 cf. Oliver, Sacred gerusia, p. 87, nº 5 y pág. $105, n^{\circ} 20$ respectivamente.

8 Cf. H. Engelmann, «Ephesiaca», ZPE 121, 1998, pp. 308-9; id., «Neue Inschriften aus Ephesos XIII», ÖJh 69, 2000, pp. 84-5, con referencia a otras inscripciones de la calle del puerto que mencionan esta gimnasiarquía $(1143,1145,1150-1)$.

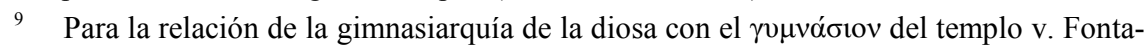
ni, ob. cit. La inscripción 3066, encontrada en el agora y fechable en el 105 d.C., aparte de mencionar esta gimnasiarquía, alude a la contribución para la construcción de este nuevo $\gamma v \mu-$ vóoıv. Además hay otra inscripción procedente del área del Artemision, del 115-6 d.C. 


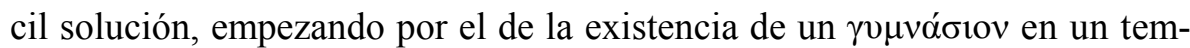
plo, para la que no hay ninguna huella arqueológica ni paralelo. Pero además, si se cotejan la inscripción publicada por Engelmann y la $n^{\circ} 1143$, ambas halladas en la calle del puerto y con un listado de diversas gimnasiarquías de la diosa y de los efebarcos y nearcos en la primera inscripción y de nearcos en la segunda relacionados con dichas gimnasiarquías, destaca el hecho de que el nearco de la decimocuarta gimnasiarquía (la única bien conservada a la vez en las dos inscripciones), no coincide. ¿Podemos pensar en una nueva gimnasiarquía que comienza con la construcción del nuevo

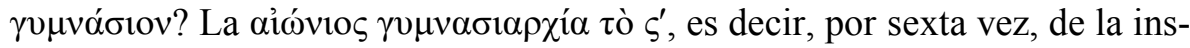
cripción del 115-6 d.C. hallada en el templo $\left(\mathrm{n}^{\circ} 1500\right)$ ¿hace referencia a la sexta gimnasiarquía en esta segunda fase, atestiguando quizá la puesta en

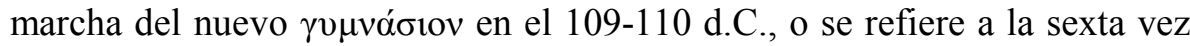
que detentan el cargo los dos gimnasiarcos mencionados? Por otra parte, la mención de un sacerdote de los efe[bos?] y gimnasiarco (836), y de un sacerdote que se encarga de la $[\pi \alpha 1 \delta 1] \grave{\alpha} \dot{\varepsilon} \varphi \eta \beta 1 \kappa \alpha ́(1145)^{10}$ hacen pensar en una relación especialmente estrecha de los efebos y véor con el templo. Gimnasiarcos de Ártemis están atestiguados también en época de Antonino Pío (1041) y en época de Cómodo (1061), en este último caso como epóni-

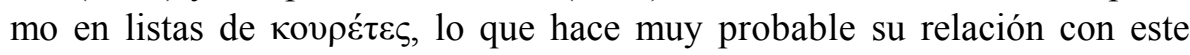

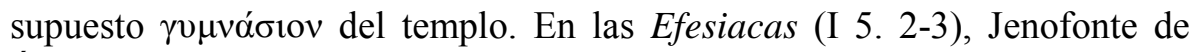
Éfeso dice que, después de haberse visto los dos jóvenes en la procesión, Habrócomes volvió a sus ejercicios acostumbrados y Antía a celebrar el culto de la diosa como solía y que eso ocurrió durante mucho tiempo, y más adelante añade que se pasaban el día en el templo de la diosa contemplándose el uno al otro. ¿Quiere eso decir que Habrócomes iba diariamente a

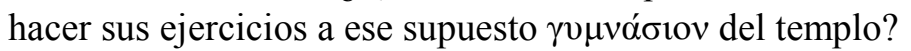

Si todavía existían en su época, Habrócomes pasaría por las dos fases en las que, al menos en el s. II a.C. (1101), se dividía la etapa de $\pi \alpha \tilde{\varsigma} \varsigma$ en Éfeso:

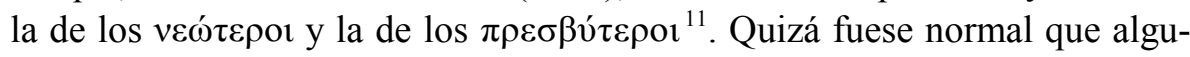

(1500), en la que dos gimnasiarcos de dicha gimnasiarquía aparecen como epónimos en la dedicación de una estatua a Trajano, y en la que muy probablemente se pueda suplir "templo"

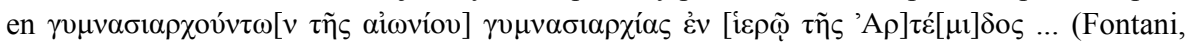
ob. cit., pp. 264-6). Cf. $n^{\circ} 938$.

10 Keil (com. al $n^{\text {o }}$ cit.) interpreta el término $\pi \alpha \imath \delta ı \alpha ́$ como traducción del latín ludus.

11 Esta clasificación, incluso en tres etapas, se conoce en otros lugares (v. L. Moretti en B. Bandinelli, Historia y civilización de los griegos. La sociedad helenística, Barcelona 1983 (trad. del it., Milán, 1977), p. 165 con n. 220). 


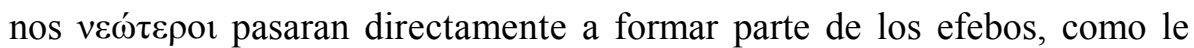

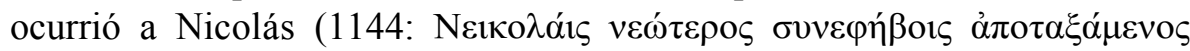
$\pi \alpha[\tilde{i} \varsigma$ ? $]--)^{12}$.

Siendo ya efebo, a los 15 o 16 años ${ }^{13}$, Habrócomes sin duda participó, como era normal entre los efebos de todas las ciudades, en muchos actos sociales importantes. El canto de los himnos al emperador había sido adjudicado por Claudio a los efebos ca. 44 d.C. (cf. $\mathrm{n}^{\circ}$ 17-19) para reducir gastos en las ciudades de Asia. "A éstos - dice - se ajusta especialmente esta $\lambda \varepsilon ı \tau o v \rho \gamma i ́ \alpha$ debido a su edad, su dignidad y su disposición para aprender» $(17,1.55)$. Por eso, cuando Adriano visitó la ciudad, Habrócomes le cantó himnos en el teatro con sus compañeros $(1145)^{14}$. También participó durante sus años de efebo en la gran procesión que iba de la ciudad al templo con motivo de la gran fiesta de Ártemis, en la que conoció, entre las doncellas que precedían la comitiva de los efebos, a su futura mujer Antía (Efesíacas, I 2.2ss.). El papel de los efebos en la vida social y religiosa de la ciudad queda reflejado en la famosa fundación de Vibius Salutaris (27), del 104 d.C., quizá el testimonio más interesante sobre los $\pi \alpha \tilde{i} \delta \varepsilon \varsigma$ y efebos de Éfeso. A

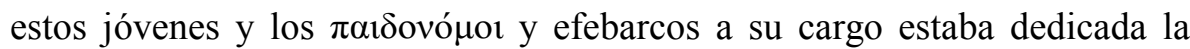

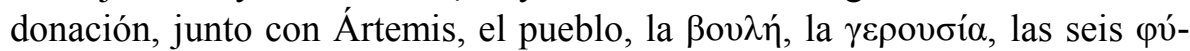

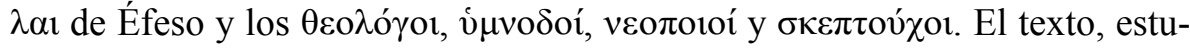
diado con detalle por G.M. Rogers ${ }^{15}$, demuestra que $\pi \alpha \tilde{i} \delta \varepsilon \varsigma$ y efebos, sobre todo los últimos, eran considerados dos de los representantes principales de la población. De las nueve estatuas de la diosa que dedica Salutaris, una, a imagen de las que ya existen en las exedras efébicas, está dedicada a los efebos, y de las otras 20 estatuas una representa a la efebía. También los $\pi \alpha \tilde{i}-$ $\delta \varepsilon \varsigma$, aunque en un añadido posterior, reciben una estatua de Atenea Pammousos para que sea colocada en su bloque del teatro. Las bases de las esta-

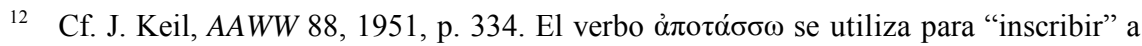
unos efebos en Dalmacia en el s. I d.C. (CRAI 1939, p. 222 A 13, 224 B 11). En la inscrip-

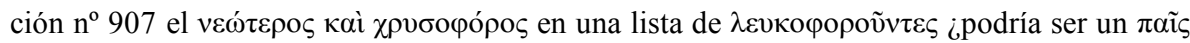


1132, del s. II d.C.

13 Cf. n. 2.

14 Los í $\mu \nu \omega \delta$ oí que tienen un dinero adjudicado en la donación de Vibius Salutaris, del 104 d.C., es decir, anterior a la estancia de Adriano en Éfeso, son posiblemente v́ $\mu \nu \omega \delta$ oí de la

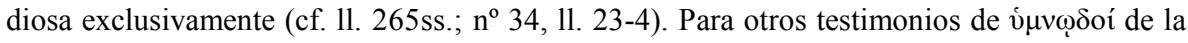
diosa v. G.M. Rogers, The Sacred identity of Ephesos, Londres, 1991, p. 55, n. 80.

15 Cf. n. anterior. 
tuas de los efebos y la de Atenea se conservan todavía, la primera dedicada a los efebos y a Ártemis ( $\left.\mathrm{n}^{\circ} 34\right)$, la segunda a los $\pi \alpha \tilde{\delta} \delta \varepsilon \varsigma, \pi \alpha 1 \delta o v o ́ \mu o r ~$ y $\pi \alpha 1-$ $\delta \varepsilon v \tau \alpha i ́$ ( $\left.n^{\circ} 33\right)$. Además un porcentaje alto de los intereses de la fundación estaban destinados a ser distribuidos entre 250 efebos, y uno más bajo entre $49 \pi \alpha \tilde{\delta} \delta \varepsilon \varsigma$ (63 en un añadido posterior según la lectura de Rogers) en el día del cumpleaños de la diosa. A cambio, los efebos tenían que acompañar a las estatuas de la diosa parte del recorrido cuando eran llevadas del templo al teatro en ocasión de las asambleas o agones. A juzgar por esta inscripción, todos los efebos de cada año estaban a cargo de un solo efebarco, lo que confirman otros testimonios (1550), los $\pi \alpha \tilde{\delta} \delta \varepsilon \varsigma$ en cambio a cargo de va-

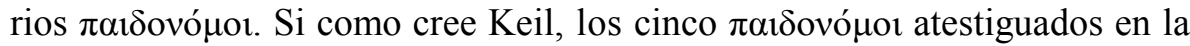
dedicación de Eumenes del s. II a.C. están relacionados con las cinco tribus existentes entonces en la ciudad, la costumbre debió de cambiar, pues parece que en época de Salutaris, en que el número de tribus había aumentado a

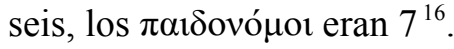

No tenemos información sobre el papel de los efebarcos. Su relación en

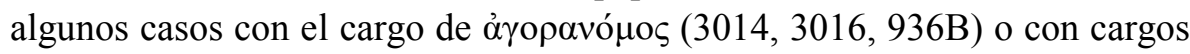
cultuales $(965,1579)$ como ocurre con los gimnasiarcos, y el hecho de que

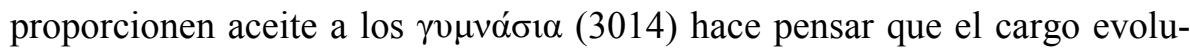
ciona hacia una $\lambda \varepsilon ı \tau o v \rho \gamma i ́ \alpha$ y tiende a confundirse con el de gimnasiarco. $\mathrm{Su}$ papel en la celebración del cumpleaños de la diosa está atestiguado, además

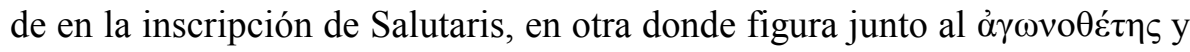
los efebos $(1151)^{17}$.

De las funciones de los $\pi \alpha 1 \delta o v o ́ \mu o r ~ e f e s i o s ~ t a m p o c o$ tenemos ninguna huella. Sólo sabemos que pertenecían a la élite efesia a juzgar por otros cargos que desempeñaban ${ }^{18}$. En Mileto, un testimonio de una mujer $\pi \alpha 1 \delta o v o ́-$ $\cos$ (Milet I 7. 265) hace pensar en un cargo de tipo litúrgico, pero a la vez, un testimonio de Iasos (IIasos 99) y otro de Milasa (IMyasa II 909) apuntan

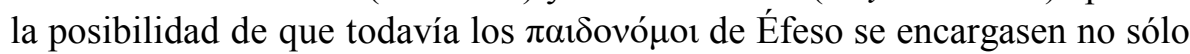

16 Cf. Rogers, ob. cit., cuadro en p. 60. Aunque el autor no justifica el número, parece claro que se deduce a partir de las cantidades señaladas en la donación para $\pi \alpha i \tilde{\delta} \varepsilon \varsigma$ y $\pi \alpha 1 \delta$ ovó$\mu o 1$, si se tiene en cuenta que por ases se entiende unas monedas de plata que equivalen a una decimoctava parte del denario (cf. ob. cit., p. 40).

17 Cf. otros testimonios de efebarcos en $n^{\circ} 724$ y 2288B (altar funerario).

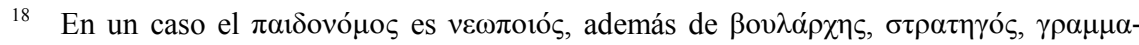
$\tau \varepsilon v ́ \varsigma$, etc. (SEG 34.1103), y en otro, además de desempeñar otros cargos, también fue efebarco (SEG 34.1093). 
de los agones, $\alpha^{\prime} \theta \lambda \alpha$ y $\theta \varepsilon o \rho i ́ \alpha$, sino también de la $\alpha \gamma \omega \gamma \eta ́$ y $\pi \alpha 1 \delta \varepsilon i ́ \alpha$ de los $\pi \alpha \tilde{i} \delta \varepsilon \varsigma$.

Por desgracia no conocemos los nombres de los compañeros de Habrócomes, pues las listas efébicas conservadas $(899,903,905 \mathrm{~A}$, probables; 904 A, la única segura) datan del s. I a.C.

A partir de aquí tenemos que imaginarnos lo que hubiese sido de Habrócomes si la vida no le hubiese deparado un derrotero tan complicado, o quizá lo que fue de él después de esa larga interrupción. En primer lugar tendremos que preguntarnos si pasó a la categoría de $v \varepsilon ́ o \varsigma$, y con esta pregunta nos enfrentamos a un problema. Los testimonios de véor $(6,1102,252,1992$; ÖJh. 62, 1993, p. 124, nº 14) son escasos. Al parecer, el más tardío data del 92-3 d.C. ${ }^{19}$, y no son mencionados en la fundación de Salutaris aunque según Estrabón (XIV 1.20) destacaban en los banquetes que se celebraban en la fiesta anual de la diosa en Ortigia. Por otra parte existe una lista de nearcos y otra de nearcos y efebarcos fechados mediante diversas gimnasiarquías de la diosa (1143, ÖJh 69, 2000, p. 84, no 17 ) a comienzos del s. II, y el nombre de un nearco figura junto al de un efebarco en la inscripción sobre los efebos que cantan himnos a Adriano (1145). El término, nuevo como nombre común, se deja entender fácilmente a partir del de efebarco pero implica lógicamente la existencia de véor ¿Por qué no hay testimonios de véor en esta época? Diversos testimonios minorasiáticos nos hacen pensar que amenudo véor y efebos no estaban separados en la práctica. En Éfeso imperial no parece que hubiera $\gamma v \mu v o ́ \sigma ı \alpha$ diferentes para los dos grupos; en

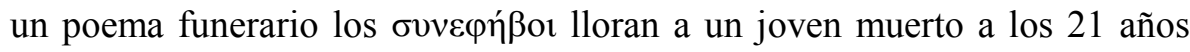
(edad que corresponde a la categoría de véos) porque tiene que abandonar la $\tau \dot{\chi} \chi \vee \eta$ y $\sigma o \varphi^{\prime} \alpha^{20}$. Las instituciones educativas y los términos no eran comunes a todas las ciudades y tampoco fijos en cada una. Es posible que en Éfeso se generalizase el término efebo para referirse a ambos grupos a la vez. Parece que un aspecto en el que sí tenían funciones diferentes era el religio-

19 Se trata de una dedicación de los véor a Domitia Sebasté, fechable gracias a la mención de P.Calvisio Ruso, bien conocido en la prosopografía efesia. Cf. D. Knibbe- H. Engelmann- B. Iplikçioğlu, ÖJh. 62, 1993, p. 124, nº 14.

20 Ç. Içten- H. Engelmann, ZPE 120, 1998, pp. 85-6, nº 6. En Mileto por ejemplo los

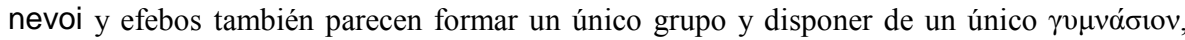

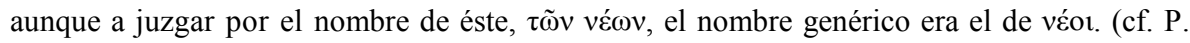
Herrmann, Milet VI 1, p. 69 con n. 3). Para otros ejemplos que atestiguan la falta real de distinción entre efebos y véor v. Forbes, Neoi. A contribution to the Study of Greek Associations, Connecticut, 1933. 
so, y curiosamente los testimonios de nearcos que tenemos están relacionados con la gimnasiarquía de la diosa Ártemis, aunque en inscripciones pro-

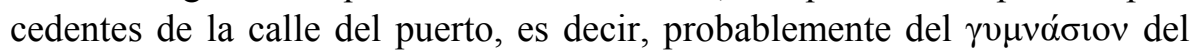

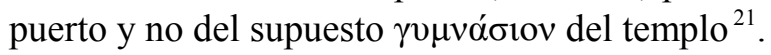

De la educación intelectual que recibió Habrócomes tenemos una huella en las exedras que se encuentran en casi todos los $\gamma v \mu v \alpha ́ \sigma ı \alpha$ en un lado de la palestra, enfrente de la exedra de culto al emperador. Sin embargo no hay ni un solo testimonio epigráfico sobre el tipo de enseñanzas que se impartían, sobre las clases regulares, conferencias, posibles profesores de paso. Los términos $\sigma \chi 0 \lambda \eta ́$ y $\alpha \kappa \rho o ́ \alpha \sigma ı \varsigma$ no aparecen ni una sola vez en los documentos de Éfeso (sólo $\sigma \chi 0 \lambda \alpha \dot{\zeta} \omega$ en un epitafio). Si se mantenía la tradición helenística, Habrócomes recibió clases de educación física, dibujo, música y gramática mientras perteneció a la categoría de $\pi \alpha i \tilde{\varsigma}$, y además participó en las pruebas o $\dot{\varepsilon} \pi \mathrm{\imath} \delta \varepsilon \dot{\xi} \xi \varepsilon 1 \zeta$ en las que alumnos y maestros demostraban sus cualidades (1101). Para imaginar lo que aprendió, veamos en primer lugar los testimonios sobre maestros.

El término $\delta ı \delta \alpha ́ \sigma \kappa \alpha \lambda \circ \varsigma$ es vago en exceso y por tanto de información poco valiosa ${ }^{22}$.

Un sentido ligeramente más concreto tiene el término $\pi \alpha 1 \delta \varepsilon v \tau \eta ́ \varsigma$, que en la lista de vencedores de pruebas para los $\pi \alpha \tilde{i} \delta \varepsilon \varsigma$ de época helenística (1101)

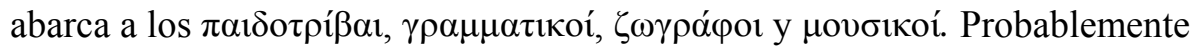

21 Un testimonio muy fragmentario y por tanto dudoso de véor es la inscripción 1992. Rogers (ob. cit., pág. 69) explica la ausencia de los véor en la donación de Salutaris, igual que la de muchos cargos cultuales importantes, basándose en su interpretación de la donación como un acto principalmente educativo, no dirigida por tanto a los que ya habían sido educados previamente y ya estaban iniciados en las fiestas de la diosa.

22 En la carta de Caracalla a Éfeso en la que alude a uno de los embajadores de la ciudad, el orador Elio Antípatro, como amigo y $\delta ı \alpha ́ \sigma \kappa \alpha \lambda o \varsigma$ suyo (2026), el término probablemente tenga el sentido amplio de preceptor (sobre este orador v. Philostr. VS 2 24, 25.4; G.W. Bowersock, Greek sophists in the Roman Empire, Oxford 1969) y quizá tenga la misma

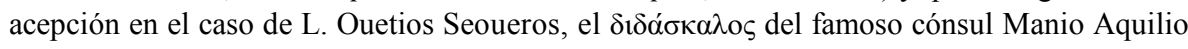
Glabrio del s. II (611; cf. R. Merkelbach, ZPE 7 (1971), p. 43s. para el cónsul, llamado бo-

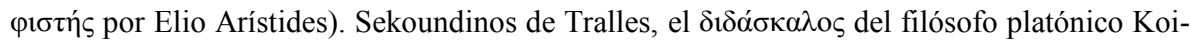
los Markellinos (4340), era probablemente un maestro de filosofía o retórica que, como era frecuente, se había ido a otra ciudad a abrir su escuela. Cf. un decreto honorífico milesio de

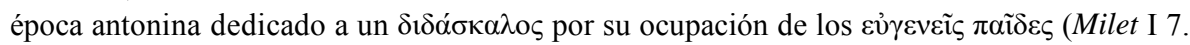
259). P. Herrmann (Milet VI 1, Nachtrag zu I 7, nº 25, pp. 203-6) considera la posibilidad de que se mencione en el texto algún tema de sus clases o de una conferencia u obra literaria, lo que hace pensar que quizá se tratara de un $\gamma \rho \alpha \mu \mu \alpha \tau$ «ós. 
el término también haga referencia a todos los maestros de los $\pi \alpha i \tilde{\delta} \varepsilon \varsigma$ en la base de la estatua de Atenea Pammousos que Fabio Salutaris dona a la ciudad en el 104 d.C., dedicada a Ártemis, a los $\pi \alpha \tilde{i} \delta \varepsilon \varsigma, \pi \alpha ı \delta o v o ́ \mu o r ~ y ~ \pi \alpha ı \delta \varepsilon v-$

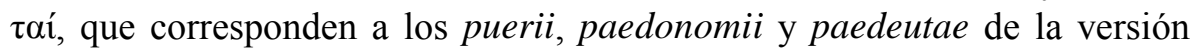
latina que precede a la griega (33).

En las otras cuatro inscripciones de Éfeso en que se menciona el término,

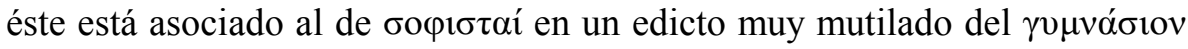
del teatro que parece ocuparse de los derechos de estos dos colectivos (216) y en la inscripción del Museo en la que se conceden diversos privilegios a

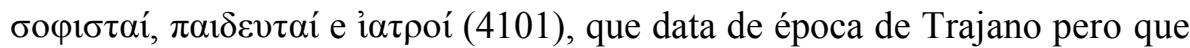
según Bringmann sería una traducción de un texto latino de época del segundo triunvirato, en el que se hablaría de grammatici et rhetores ${ }^{23}$. Según la interpretación de este autor, el término $\pi \alpha 1 \delta \varepsilon v \tau \alpha i ́$ designaría en esta época a los $\gamma \rho \alpha \mu \mu \alpha \tau$ коí. Aparte de la ausencia de paralelos para esta acepción tan restringida, sería raro que un griego tradujera el latín grammatici con un término distinto de $\gamma \rho \alpha \mu \mu \alpha \tau$ «ós, el técnico y de origen griego para designar a los profesores de lengua y literatura. Para traducir el término griego $\pi \alpha 1 \delta \varepsilon v-$ $\tau \alpha i$ en latín del s. II d.C. se utilizaba paedeutae como se puede ver en la inscripción $n^{\circ} 33$ del 104 d.C. ¿No sería más lógico que $\pi \alpha ı \delta \varepsilon v \tau \alpha i$, de ser realmente una traducción del latín, tradujera un término como praeceptor, que aparece por ejemplo en un decreto de Augusto del año 6 a.C. en el que a causa del hambre que asola la ciudad obliga a todos los extranjeros y otros grupos a salir de Roma, eximiendo de esta orden expresamente a los medici et praeceptores? ${ }^{24}$ En Éfeso los $\pi \alpha 1 \delta \varepsilon v \tau \alpha i ́$ se agrupaban, igual que los médi-

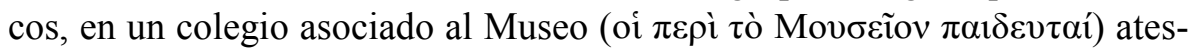
tiguado por dos inscripciones de época romana $(2065,3068)^{25}$. Estos $\pi \alpha \mathrm{l}$

${ }^{23}$ K. Bringmann, «Edikt der Triumvirn oder Senatsbeschluss? Zu einem Neufund aus Ephesos», Epigr. Anat. 2, 1983, pp. 47-76, esp. 51-3.

${ }^{24}$ El decreto (cf. Suet., Diu. Iul. Aug. 42) lo cita el propio Bringmann (ob. cit., p. 69, n. 107). Por otra parte Antonino Pío, en su carta al Koinon de Asia (Dig. 27.1.6), habla de la limitación de la exención de impuestos a un número determinado de médicos, sofistas y $\gamma \rho \alpha \mu-$

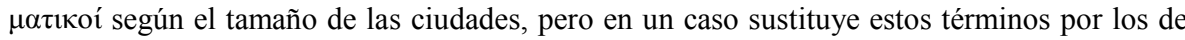

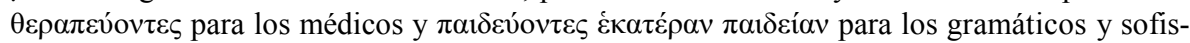

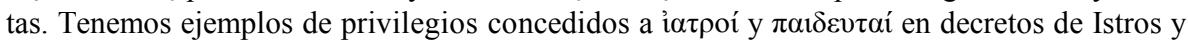
de Dionysopolis en Tracia (v. L. Robert, «Les inscriptions greques de Bulgarie», RevPhil., 1959, p. 206s.; id., Bull. Ép., 1962, no 239) o en un decreto de Vespasiano en Pérgamo (Mc Crum- Woodhead, Select Documents of the Principate of the Flavian Emperors, Cambridge, 1961, nº 458).

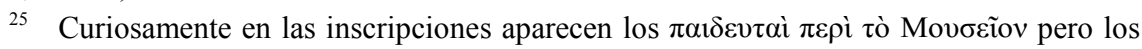


$\delta \varepsilon v \tau \alpha i$ eran probablemente todos los profesores de $\pi \alpha \tilde{i} \delta \varepsilon \varsigma$ y efebos, incluidos los de educación física, como ocurría ya en época helenística $(1101)^{26}$. Es posible que el texto fuese una traducción de un texto latino anterior, como opina Bringmann, y que los cambios terminológicos e incluso institucio-

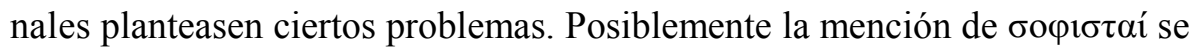
debiese a un deseo de traducir expresamente rhetores del latín, o quizá a que los sofistas no estaban incluidos entre el resto de los $\pi \alpha 1 \delta \varepsilon v \tau \alpha i ́$ en Éfeso, a pesar de que no esté atestiguada una asociación específica de sofistas en relación con el Museo.

Habrócomes recibió clases de un $\gamma \rho \alpha \mu \mu \alpha \tau \iota \kappa o ́ s$, aunque probablemente, por razones cronológicas, no del único atestiguado epigráficamente con toda seguridad en Éfeso imperial, Isidoro hijo de Isidoro (956a), que tenía el privilegio de ser uno de los cinco $\gamma \rho \alpha \mu \mu \alpha \tau$ «ó que disfrutaban de la exención

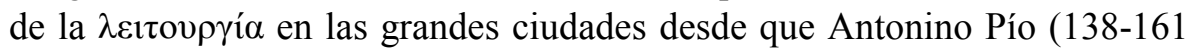
d.C.) puso límites a la concesión de este privilegio ${ }^{27}$. El único otro posible

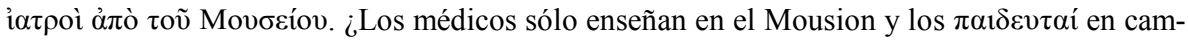

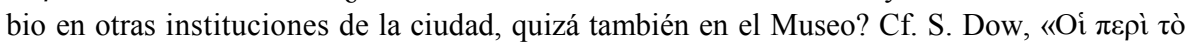

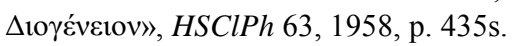

26 La aplicación del término $\pi \alpha ı \delta \varepsilon v \tau \alpha i ́$ a los profesores de enseñanza superior la confirma su relación con los efebos y véot, además de los $\pi \alpha \tilde{i} \delta \varepsilon \varsigma$, por ejemplo en Iulia Gordos (ya en el s. I a.C.), Pérgamo y Gallipoli en los Dardanelos, o con efebos y $\pi \alpha \tilde{l} \delta \varepsilon \varsigma$ en la zona del Caico, o sólo con los efebos en Milasa o con los véoı en Esmirna (J. y L. Robert, Hellenica VI, París, 1948, p. 90s.; MusBiblSmyrn II 1 (1875-6) 18, n 31; IMylasa 118; ISmyrna 215

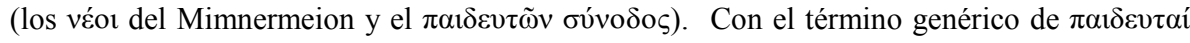
son denominados los funcionarios (no sólo profesores) de los gymnásia atenienses en época helenística (IG II/III $\left.{ }^{2} 1.1039-43\right)$. También son denominados $\pi \alpha \iota \delta \varepsilon v \tau \alpha i ́$ en general los profe-

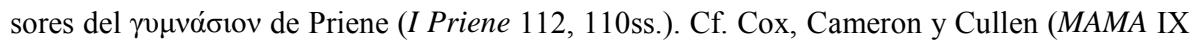
477), para quienes el término parece cubrir, además de la profesión de maestro, las más espe-

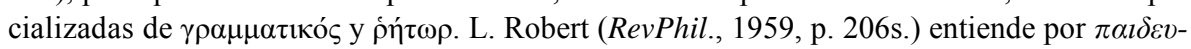
$\tau \alpha i$ todos los profesores, tanto los de educación física como los de letras ¿Será por iniciativa de los $\pi \alpha 1 \delta \varepsilon v \tau \alpha i$ de educación física por lo que la agrupación mencionada del Museo dedica una inscripción a una $\lambda \alpha \mu \pi \alpha \delta \alpha ́ \rho \chi \eta \varsigma$ de la diosa (3068)?

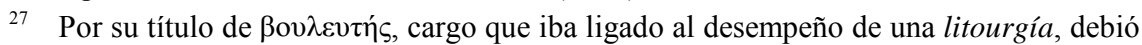

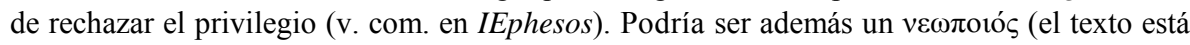

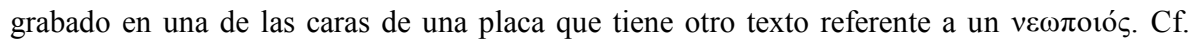
Keil-Maresch, ÖJh 45, 1960, pp. 93-4, nº 20b; Knibbe, ÖJh 46, 1961, p. 26. Para la exención

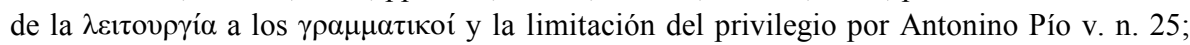
Bringmann, ob. cit., pp. 69-73, sobre los privilegios de los distintos cuerpos docentes y los médicos en los distintos momentos del imperio; cf. Parson, en Hanson (ed.), Collectanea Papyrologica 2, Bonn, 1976, pp. 441-6. 
testimonio de $\gamma \rho \alpha \mu \mu \alpha \tau$ «oí en Éfeso es la inscripción helenística 1101 ya mencionada, donde el término sin embargo está suplido.

En general, los $\gamma \rho \alpha \mu \mu \alpha \tau$ เoí atestiguados en las ciudades minorasiáticas, aunque extrañamente escasos, revelan que el cargo era ostentado a menudo por personas de alta posición y que eran objeto de admiración por parte de la comunidad y en muchos casos representantes de la cultura de la ciudad a

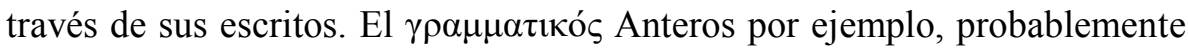
de Milasa, que ejerció la enseñanza en Atenas en el s. II como demuestra un decreto de Labraunda, destaca como educador de los jóvenes de la ciudad y profesor de jóvenes venidos de otros lugares. Además es literato y ha compuesto historias sobre las bellezas de su patria ${ }^{28}$. El $\gamma \rho \alpha \mu \mu \alpha \tau \iota \kappa o ́ s ~ E u a r e s t o s$ de Oinoanda, fundador de importantes agones en la ciudad en la segunda mitad del s. III d.C., también $\dot{\alpha} \lambda \varepsilon i \tau o v ́ \rho \gamma \varepsilon \tau o \varsigma$, confiesa en un poema elegíaco

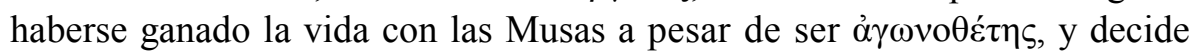

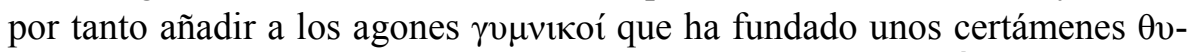
$\mu \varepsilon \lambda \iota \kappa o i ́\left(\right.$ artísticos) ${ }^{29}$. No sabemos si el gramático Isidoro de Éfeso daba clases en un $\gamma v \mu v \alpha ́ \sigma i o v$, como por ejemplo uno de los gramáticos atestiguados en Delfos en el s. I a.C. (FDelph III 3.338), o si tenía su propia escuela.

Si Habrócomes se decidió a proseguir sus estudios una vez repuesto de sus andanzas, iniciaría su enseñanza superior con sofistas y filósofos.

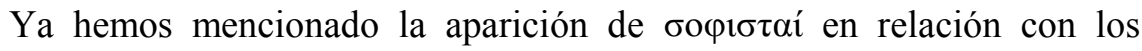
$\pi \alpha 1 \delta \varepsilon v \tau \alpha i$ en dos inscripciones (216 y 4101) que se refieren, la primera con seguridad y la segunda probablemente, a derechos y privilegios de estos cuerpos docentes. Esta acepción de sofista, término peyorativo en época helenística y comienzos de la romana, no empieza a estar atestiguada hasta finales del s. I d.C. y a ser normal hasta el $\mathrm{II}^{30}$. Los demás testimonios del término hacen referencia a cinco sofistas concretos que viven a lo largo del s. II y comienzos del III d.C. ${ }^{31}$ Uno de ellos, Soteros, tiene entre sus discí

28 J. Crampa, Labraunda. Swedish excavations and researches III 2: The Greek Inscriptions II, Estocolmo, 1972, p. 136 a no 66 (L. Robert, Bull.Épigr., 1973, n 414). Cf. S. Agus-

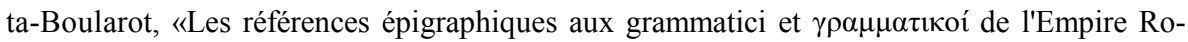
main», MEFRA 106, 1994, pp. 653-746 para los testimonios de $\gamma \rho \alpha \mu \mu \alpha \tau$ al IV d.C., en concreto para esta inscripción, $\mathrm{n}^{\mathrm{o}} 42$ (cf. 41, 47).

29 A. Hall- N. Milner, Education and Athletics, en D. French (ed.), Studies in the History and Topography of Lycia and Pisidia, Ankara, 1994, pp. 7-47, $\mathrm{n}^{\circ}$ 18b, cf. 10, 14, 15.

30 Cf. Bringmann, ob. cit. en n. 24, p. 51s.

31 Po. Hordeonios (984), Soteros (1548), Dionysos (3047) y dos sofistas cuyos nombres 
pulos dos efesios, tres rodios, un hierapolites, un niceo, un antioqueo de Pisidia, un foceo, un anquirano y un caunio ${ }^{32}$. En el epigrama que acompaña

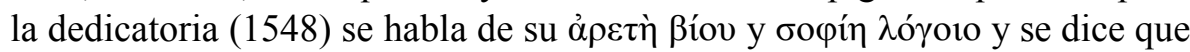
fue llamado dos veces por los androclidas (los efesios) para que fuese de

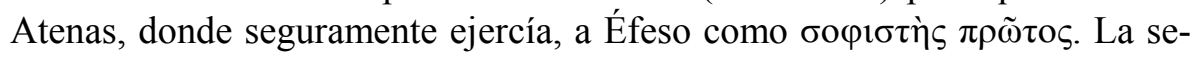
gunda vez se le ofrecía el incentivo de un sueldo anual de 10.000 dracmas, la misma cantidad que percibía del estado romano el ocupante de la cátedra de sofística en Atenas. Estos datos no concuerdan con las palabras que le dedica Filóstrato, quien no le considera digno del nombre de sofista ${ }^{33}$. Hordeonios Lollianos (984), perteneciente a una familia itálica de la que dos ramas se encuentran atestiguadas ya como asentadas en Éfeso, ejercía su profesión en Atenas, donde según Filóstrato (VS 1.23) le fueron dedicadas dos estatuas honoríficas, una de ellas quizá la aparecida en la acrópolis (IG $\left.\mathrm{II}^{2} 4211\right)^{34}$. El nombre del famoso sofista Damiano se encuentra asociado a

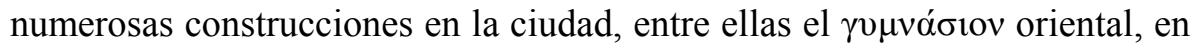
el que ha aparecido una estatua suya con la cabeza conservada ${ }^{35}$. Otros sofistas famosos del s. II-III d.C. estuvieron temporalmente en Éfeso, como Herodes Ático, al que la ciudad dedicó una estatua de la que se conserva la placa superior del basamento con su nombre (640), o Elio Arístides (cf. Hieroi Logoi $2.83,5.35)^{36}$. Con puesto oficial estuvo en Éfeso el discípulo de Arístides, Hadrianos, que dedicó una inscripción honorífica en prosa y verso (1539) al filósofo Claudio Severo ${ }^{37}$.

En el mismo espacio temporal están atestiguados epigráficamente en Éfeso cuatro rétores ${ }^{38}$. En la base de una estatua que le dedican la boule y el

no se conservan $(825,826)$. Sobre los testimonios literarios y epigráficos de la segunda sofística en Éfeso, v. J. Keil, «Vertreter der zweiten Sophistik in Ephesos», ÖJh 40, 1953, pp. $5-26$.

32 Entre los discípulos hay algunos conocidos por otras fuentes, que ocupan cargos importantes (v. com. a IEphesos 1548).

33 Philostr., VS II 23. Para esta inscripción en general, y una dedicación honorífica que recibe Soteros en Delfos (FDelph. III 4, n 265) v. Keil, ob. cit., pp. 15-18.

34 Cf. J. Keil, ob. cit., pp. 7-12.

35 Cf. Philostr., VS 2.23; Keil, ob. cit., pp. 18-20.

36 Sobre la presencia de estos dos sofistas en Éfeso cf. Keil, ob. cit., pp. 12-3.

37 Philostr., VS 2.23; Keil, ob. cit., pp. 13-5. Para la estancia de Aidesios de Capadocia, discípulo de Jámblico, en Efeso v. Keil, ob. cit., p. 24s. y, para el testimonio de un sofista efesio en Ostia, p. 21.

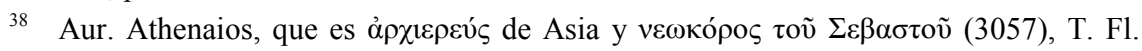


demos a uno de ellos, el famoso Ti. Kla. Phlaouianós Dionysios (3047), éste aparece como rétor y sofista, quizá para destacar su doble faceta de orador además de profesor de retórica ${ }^{39}$. De los atestiguados sólo como rétores en las inscripciones no habla Filóstrato en sus Vidas de los sofistas, sí en cambio de Dionysios, Lollianos y Soteros, sofistas según la epigrafía.

Habrócomes pudo recibir clases de un sofista en una escuela privada, cuyo funcionamiento quizá fuera parecido al de la escuela del sofista Proclo en Atenas que nos describe Filóstrato (VS 2.21), pero no podemos descartar la posibilidad de que el Museo fuese un centro de enseñanza ${ }^{40}$. La importancia de Éfeso como centro de retórica puede verse en las procedencias de los alumnos que asistieron a las clases de Sotero. No sabemos a qué edad empezaría un joven su enseñanza superior, sólo tenemos el testimonio de un efesio que murió en Lesbos en el s. I d.C. a los 20 años, que desde hacía poco

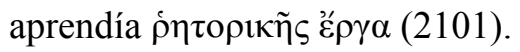

Pero Habrócomes pudo inclinarse por la filosofía, o posiblemente estudiarla además de retórica, y pudo elegir entre las principales escuelas filosóficas del momento. Al menos existen testimonios en Éfeso de un filósofo ecléctico procedente de Alejandría (789), un filósofo peripatético (616) y dos filósofos platónicos, uno de ellos, Sekoundinos, procedente de Tralles (4340) y otro el famoso Ophellios Laitos (3901), al que se le dedica una es-


$\grave{\alpha} \rho \varepsilon \tau \eta ́ v)$ y un dístico igual al que recibe en una inscripción de Atenas $\left(I G \mathrm{II}^{2}\right.$ 3816), por el que se le considera el mejor filósofo platónico: «si como dice Pitágoras, el alma pasa a otro, en tí, Laitoe, vive Platón, de nuevo liberado», versos que proceden de una larga tradición literaria ${ }^{41}$. Un fragmento recien

Menandrou y su hijo de igual nombre, ambos asiarcas (3062) y el famoso Ti. Kla. Phlaouianós Dionysios, de origen milesio que muere en época de Adriano (426, 3047; cf. Philostr., VS I 22; Bowersock, ob. cit. en n. 23, p. 52 (v. index, 135).

39 Sobre este famoso sofista de época de Adriano, oriundo de Mileto pero que ejerció la última parte de su carrera en Éfeso, donde murió, v. Philostr., VS 1.22; Keil, ob. cit., pp. 5-7; Jones, GRBS 21, 1980, pp. 373-4.

40 Cf. n. 25 y p. 43.

${ }_{41}$ Cf. J. Nollé, ZPE 41, 1981, p. 197-206; G.W. Bowersock, «Plutarch and the sublime hymn of Ofellius Laetus», GRBS 23, 1982, pp. 275-9. La importancia del aspecto moral es un elemento común a todas las escuelas filosóficas, pero por otra parte son frecuentes, sobre todo referidas a artistas, palabras sobre su destacada técnica y comportamiento en la vida (v. ejemplos en Nollé, ob. cit., p. 197, n. 3, algunos de Éfeso: 678, 2071). Para numerosos testimonios epigráficos de filósofos platónicos, varios de ellos así denominados expresamente, y otros de 
temente descubierto completa la inscripción honorífica $\mathrm{n}^{\circ} 1539$, revelando el término filósofo referido al cónsul del 173 d.C. Cn. Claudio Severo, yerno de Marco Aurelio e hijo de un maestro de filosofía del emperador ${ }^{42}$. La inscripción se la dedica el sofista Hadriano ya mencionado. También los filósofos realizaban a veces una carrera política, como demuestra Appios Alexan-

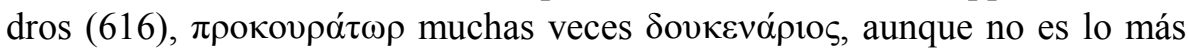
frecuente ${ }^{43}$.

Si Habrócomes hubiese muerto en el curso de su aventura, probablemente en su estela funeraria habría recibido el nombre de $\varphi \imath \lambda \hat{\lambda} \lambda \sigma \gamma o \varsigma$, como otros tres jóvenes enterrados en Éfeso, entre ellos uno de Aspendo $(2211)^{44}$ y otro

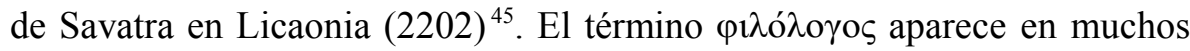
epitafios del mundo griego, y en casi todos ellos parece estar referido a jóvenes estudiantes ${ }^{46}$. Parece sin embargo una forma poética de referirse a los estudiantes, pues no es el término empleado en este sentido en decretos u otro tipo de inscripciones oficiales que hagan referencia a cuestiones institucionales ${ }^{47}$. Los paralelos de la cercana ciudad de Esmirna, más generosos en información, nos proporcionan las edades de 17 y 20 años para otros $\varphi \imath \lambda$ ó$^{-}$

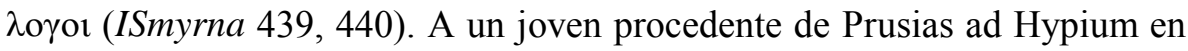

pitagóricos, v. Tod, $J H S$ 77, 1957, pp. 133-5.

42 H. Engelmann, ÖJh 69, 2000, p. 78 para el añadido del nuevo fragmento. Sobre el filósofo y para un nuevo suplemento en la 1.7 v. C.P. Jones, «Epigraphica II. Two consular philosophers», ZPE 139, 2002, pp. 111-4.

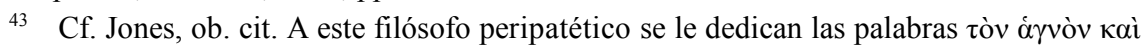

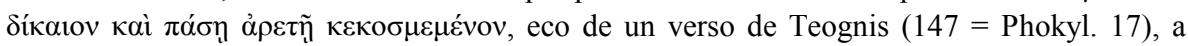
menudo citado por Platón y Aristóteles. Cf. 3039, donde el cuestor M. Aur. Sekoundinos es honrado con casi las mismas palabras. A juzgar por una inscripción latina de Éfeso, a Juliano Apóstata (361-3 d.C.) se le dedica una inscipción en latín uirtutum omnium magistro filosofiae principi uenerando (313A, cf. 3021; ISmyrna 816a; IIasos 14; IP VIII 2, 633). Por último, se menciona a un filósofo en una inscripción muy lagunosa (1958), y en un dedicación aparecida en el Artemision (4328) se transcriben los versos de un neopitagórico (Bull.Épigr., 1951, p. 198; cf. n. 42).

44 Posiblemente se trate de un joven de Aspendo que ha ido a estudiar a Éfeso acompañado de su hermano, el autor del epitafio.

45 Cf. también D. Knibbe-H. Engelmann-B. Iplikçioğlu, ÖJh 59, 1989, p. 235, nº 69.

46 Cf. L. Robert, Hellenica XIII, París, 1965, pp. 46-50, con abundantes testimonios. Sobre el término v. G. Nuchelmans, Studien über philólogos, philología und philologeîn, Diss., Nimega, 1950; H. Kuch, Philologos. Untersuchungen eines Wortes von seinem ersten Auftreten in der Tradition bis zur ersten überlieferten lexikalischen Festlegung, Berlín, 1965.

47 En Eretria, por ejemplo, un $\varphi \imath \lambda o ́ \lambda o \gamma o \varsigma$ homérico ambulante es contratado en el s. II a.C.

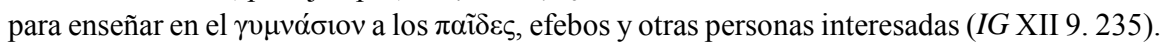


Bitinia que murió en Éfeso a los 20 años no se le llama filólogo, pero se dice

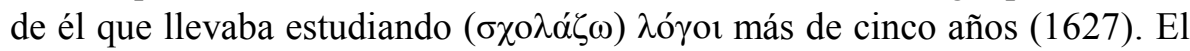
término $\lambda$ ó or debe tener aquí el mismo sentido general que su correspon-

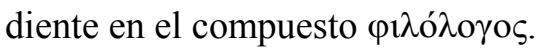

Ya hemos visto que Habrócomes participaba en algunos actos sociales importantes de la ciudad, pero no hemos hablado de los numerosos agones en los que pudo competir ya desde que pertenecía a los $\pi \alpha \tilde{i} \delta \varepsilon \varsigma$. Los testimonios de estos agones, sin estar directamente relacionados con el sistema educativo, proporcionan una valiosa información por la infraestructura cultural que reflejan. Aunque la mayoría hacen referencia a pruebas físicas (agones

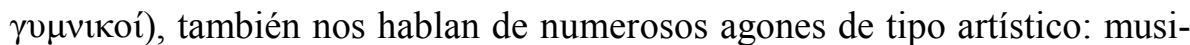

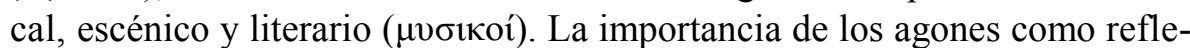
jo de la cultura de las ciudades ya ha sido puesta en relieve en los libros de Wörrle y Ziegler ${ }^{48}$.

Además de participar en agones youvıкoí, Habrócomes intervino en algu-

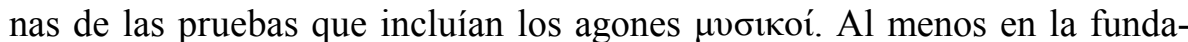
ción de Demóstenes de Oinoanda, cuyo programa, aunque más reducido, coincide en líneas generales con el de los Lisimaqueia de Afrodisias, estos agones seguían un orden de importancia de menor a mayor a juzgar por la calidad de los premios y el momento de la fiesta en que tienen lugar ${ }^{49}$.

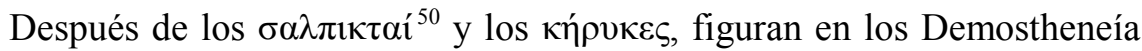

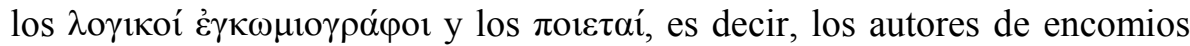
en prosa y verso. En Éfeso existía una prueba encomiográfica en los Megala Artemisia (1104A). La composición de encomios era uno de los primeros y más importantes ejercicios que se hacían en las escuelas de retórica y ya in-

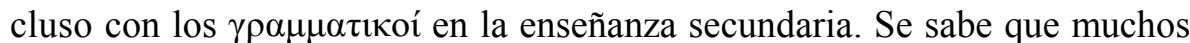
rétores famosos seguían componiendo encomios como obras literarias ${ }^{51}$.

48 M. Wörrle, Stadt und Fest in Kaiserzeitlichen Kleinasien. Studien zu einer agonistischen Stiftung aus Oenoanda, Múnich, 1988; R. Ziegler, Städtisches Prestige und kaiserliche Politik. Studien zum Festwesen in Ostkilikien im 2. und 3. Jahrhundert n. Chr., Düsseldorf, 1985. Para los agones de Éfeso v. S. Karwiese, RE, Suppl. XII, 1970, pp. 277-81. Para la in-

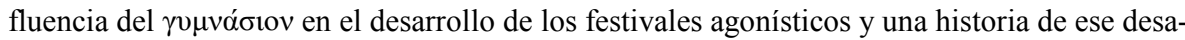
rrollo en Asia Menor en época imperial v. S. Mitchell, Anatolia I, Oxford, 1993, pp. 217-222.

49 Wörrle, ob. cit., p. 229.

50 En Éfeso aparecen mencionados siempre en relación con el culto de Ártemis, en listas de curetes y otros cargos cultuales.

51 v. Didyma 182. Para agones de discursos instaurados por emperadores en occidente v. Suetonio, Calig. 20, Domit. 4. 
Una inscripción recientemente publicada, escrita por un rétor un poco alambicado, parece testimoniar, si la interpretación de Debrunner Hall es correcta, además de un ejemplo de enseñanza retórica, la existencia de un festival

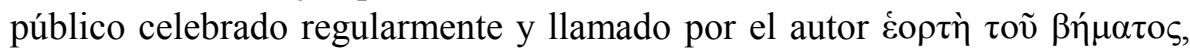
en el que este rétor debió ganar con un encomio a la ciudad ${ }^{52}$. Un $[\hat{\rho} \eta ́ \tau] \omega \rho$

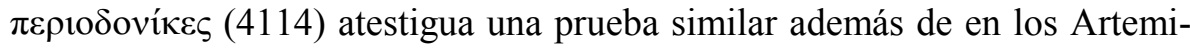
sia, en los Ephesia, Barbilleia y Hadrianeia, todos ellos festivales agonísticos de Éfeso ${ }^{53}$.

También había en Éfeso agones musicales (1618) y, más concretamente,

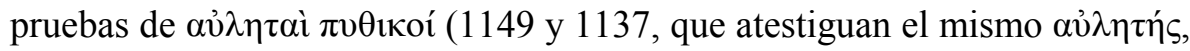
Tit. Aur. Beryllos). Según el comentario de IEphesos, el término pítico implica que es un agón para $\pi \alpha \tilde{\delta} \delta \varepsilon \varsigma$ entre 12 y 14 años, pero según L. Robert,

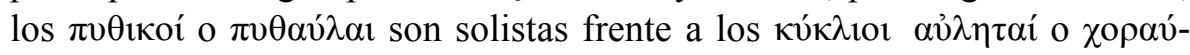
$\lambda \alpha$, que son flautistas con coro ${ }^{54}$.

A los agones musicales seguían en importancia los escénicos, primero de comedia, atestiguados en los Megala Artemisia en el s. II d.C. (1606, cf. 1147), y luego de tragedia (3814: s. III). Tanto la inscripción 1606 como la 3814 hacen referencia a $\pi \alpha \tilde{i} \delta \varepsilon \varsigma^{55}$.

Los agones de citarodos, al parecer los más importantes, están atestigua-

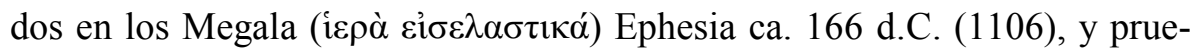
bas especiales para $\pi \alpha \tilde{i} \delta \varepsilon \varsigma$ en los Megala Artemisia en el s. III (3813) ${ }^{56}$.

En Éfeso había incluso agones médicos que se celebraban regularmente en los Megala Asklepieia con pruebas de cirugía, instrumental, tesis y problema $(1116,1162 \text { y add. 24, 1166, 1167, } 1168 \text { y } 4101 b)^{57}$. Ya hemos mencio

52 ZPE 91, 1992, pp. 121-8.

53 Aur. Athenaios, quizá el rétor de la inscripción 3057. Para los problemas de que sea

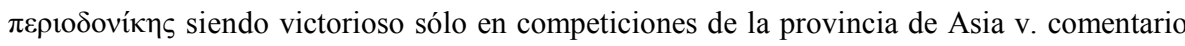
correspondiente en IEphesos.

54 L. Robert, R.Phil., 1930, pp. 54 ss. (=OMS II, Amsterdam, 1969, pp. 1154s.), que presenta testimonios de la categoría de $\pi \alpha \tilde{i} \delta \varepsilon \varsigma$ en agones musicales sobre todo de citarodos, $\mathrm{y}$ afirma que los $\alpha$ ỉ $\eta \tau \alpha i$ apenas están atestiguados.

55 L. Robert (REG 79, 1966, pp. 752s.) considera que no atestiguan la existencia de agones específicos para $\pi \alpha \tilde{i} \delta \varepsilon \varsigma$, sino la presencia de niños desempeñando papeles de niños en agones generales de tragedia y de comedia, aunque cf. id., Bull.Épigr., 1971, nº 307, referido a testimonios similares de Corinto.

56 Otros vencedores están atestiguados en D. Knibbe-B. Iplikçioğlu, ÖJh 53, 1982, p. $126 \mathrm{n}^{\mathrm{o}} 125 \mathrm{y}$, aunque perdido el nombre, 1148 .

57 Cf. Marrou, ob. cit. en n. 1, pp. 254-5. Según H. Engelmann (ZPE 84, 1990, pp. 
nado que los médicos formaban un colegio con sede en el Museo y disfrutaban de las mismas prerrogativas que los sofistas y los demás $\pi \alpha \imath \delta \varepsilon v \tau \alpha i ́$.

Son numerosas las pruebas de que Habrócomes vivía en una ciudad preocupada por la cultura.

A finales del s. II a.C. la ciudad decreta una dedicación honorífica (5) a los astipaleos por haber vencido a los piratas que habían invadido la zona de Pygela, perteneciente a Éfeso, y haber acogido en sus casas a los niños rap-

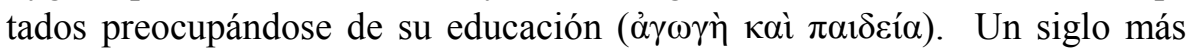
tarde, Átalo II de Pérgamo mandó llamar a un efesio para que se encargara de la educación de su sobrino, el futuro Átalo III, y en una carta que escribe a los efesios alaba las virtudes del educador ${ }^{58}$, y en el s. III d.C., en una carta

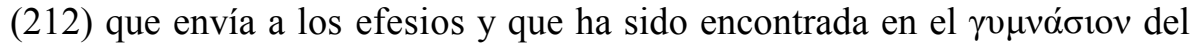
teatro, Iulia Domna desea que sean beneficiarias de actos evergéticos de su hijo Caracalla a todas las ciudades y pueblos, pero especialmente a Éfeso por ser, entre otras cosas, $\pi \alpha 1 \delta[\alpha \gamma \omega \gamma \varepsilon \tilde{o}$ v ] (o $\pi \alpha 1 \delta[\varepsilon v \tau \eta \dot{\rho t o v}]$ ) para los que

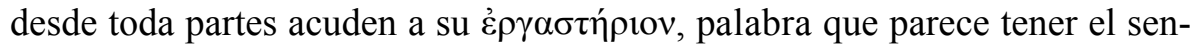
tido de "escuela' ${ }^{59}$. No son pocos los efesios que reciben dedicaciones honoríficas por haber promovido de una manera u otra la educación ${ }^{60}$. En un caso los ciudadanos se alegran de que Ártemis les haya proporcionado una $\pi \rho v$ $\tau \alpha v ı \varsigma \sigma o \varphi \eta ́$, que ofreció a la población espectáculos escénicos y musicales ${ }^{61}$. Además de los docentes y vencedores en agones mencionados, también hay testimonios de profesionales que dedican su vida a la cultura, como poetas $(1136,1149,3067 a)$, un tañedor de syrinx (al que dedica una inscripción

89-92), los fragmentos 1168 y 4101 b pertenecen a la misma inscripción.

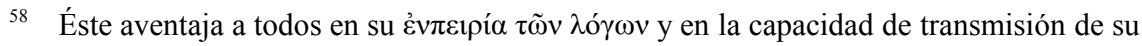
ciencia. Destaca igualmente su $\eta^{\prime} \theta$ o $\varsigma$ considerándole el más indicado para ocuparse de un joven, y señala que es evidente para todos que los $\kappa \alpha \lambda$ $\alpha \alpha \gamma \alpha \theta$ oí por naturaleza de entre los jó-

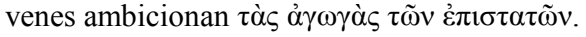

59 Lifshitz (ZPE 6, 1970, pp. 57-60) considera el término traducción del latín officina, que aparece a menudo en Cicerón en el sentido de "escuela de rétores" y que en Libanio (Or. 55.34) y Elio Arístides (29.18) tiene el sentido de "escuela" en general. Cf. Robert, R.Phil. 41,

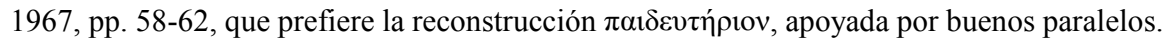



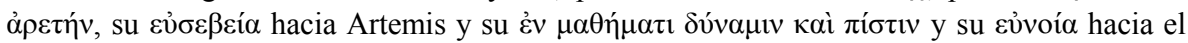

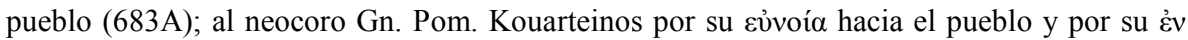

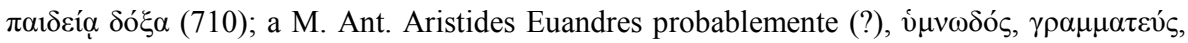

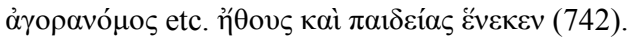

${ }^{61} 1063$, cf. 1064. 
funeraria su auletés, con una representación de un hombre sentado tocando el instrumento: 1672), actores clásicos y de mimo representados en dibujos para funciones teatrales y de mimo (2091-2093), y son numerosas las inscripciones funerarias que, sin hablar de instituciones concretas, reflejan el valor que se daba en la ciudad a la cultura, a la sabiduría, a tener experiencia en el mundo de las Musas, como reflejan la frecuente aparición de términos

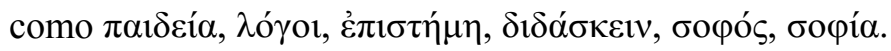

La institución del Museo, en torno a la que se asociaban maestros y médicos, y la famosa biblioteca de Celso sin duda jugaron su papel y a la vez son reflejo de la cultura de la ciudad.

El edificio del Museo está atestiguado epigráficamente por una estatua honorífica dedicada en la primera mitad del s. II d.C. a Ga. Ioul. Fabia Pon-

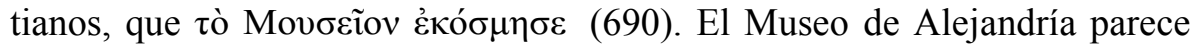
haber servido de modelo para la creación de una institución de igual nombre en varias ciudades, y son frecuentes los testimonios de filósofos, literatos o

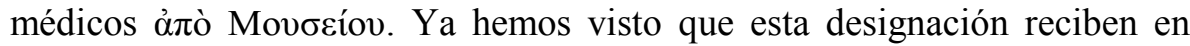
Éfeso los colegios de médicos $\mathrm{y}$, con una pequeña variante, los de $\pi \alpha 1 \delta \varepsilon v \tau \alpha i ́$ (que quizá incluyan a sofistas y filósofos). No se sabe sin embargo nada de las funciones que tenía realmente la institución, si era un lugar de enseñanza o de reuniones, o centro de trabajo de los profesionales, o simplemente una sede de los distintos colegios. El paralelo del Museo de Esmirna, que como ha demostrado Robert, estaba centrado en la faceta jurídica y servía además de archivo de la ciudad, nos hace pensar en una especialización similar en

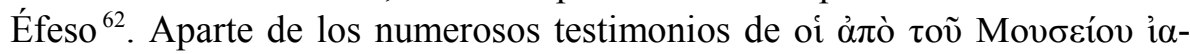

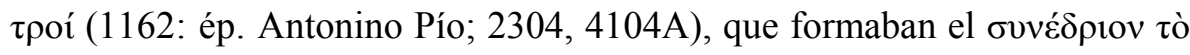

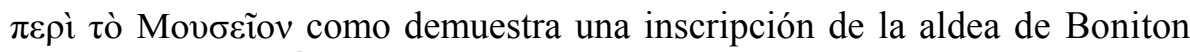
en el territorio de Éfeso (3239), tenemos los testimonios de los agones médicos ya mencionados, cuyos concursantes pertenecen a dicho synédrion, a juzgar por otra inscripción (1162).

Sin duda relacionada con la educación está la famosa biblioteca llamada de Celso que el hijo de éste, Ti. Ioulios Akylas hizo construir en honor a su padre, el cónsul y luego procónsul Ti. Oul. Kelsos Polemaianos entre el 113 y 117 d.C. $(5101,5113)^{63}$. Especialmente interesante es la segunda de estas

62 L. Robert, «Le Musée de Smyrne», Études anatoliennes, París, 1937, pp.146-8, con testimonios de Museos en otras ciudades.

${ }^{63}$ Para los testimonios epigráficos de la Biblioteca v. IEphesos VII 2, pp. 515ss.; para un estudio más arqueológico, v. H. Engelmann, «Celsusbibliothek und Auditorium in Ephe- 
inscripciones, grabada en un sillar de la fachada del edificio, que atestigua la donación, además de la construcción con todo el ornamento, de un dinero para la compra de libros. Los intereses servirían para comprar libros nuevos y para pagar a los bibliotecarios ${ }^{64}$. Parece que la biblioteca tenía cabida en su sala de lectura para 12.000 volúmenes. Es significativo que varias otras inscripciones efesias, algunas por desgracia muy lagunosas, hagan mención de libros $(22,964,5114)$.

El intento de reconstrucción de la educación en la Éfeso antigua revela inmensas lagunas en la información y deja muchas cuestiones sin resolver: algunas de tipo léxico y muchas de tipo institucional, pero creo que revela la existencia de una educación pública para los jóvenes por lo menos desde los

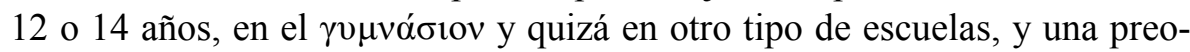
cupación constante de la ciudad por sus $\pi \alpha \tilde{i} \delta \varepsilon \varsigma$ y efebos.

La existencia de pruebas agonísticas en las distintas ramas artísticas, en muchos casos para los $\pi \alpha \tilde{i} \delta \varepsilon \varsigma$, demuestra que se seguía dedicando una atención especial, quizá más que antes, a la música y literatura. Los testimonios demuestran que los docentes y encargados de la educación, al menos secundaria y superior, pertenecen a menudo a las clases más altas y reciben honores especiales de su ciudad o incluso del emperador mediante la concesión de privilegios y ayudas económicas. La ausencia de más información y sobre todo de información más concreta no debe verse como un síntoma de la ausencia de un sistema educativo. En Éfeso sólo está atestiguado un $\gamma \rho \alpha \mu-$ $\mu \alpha \tau$ «ó́ y sin embargo sabemos por la ley de Antonino Pío ya mencionada que había más de cinco en las ciudades grandes. Posiblemente en esta época el sistema estaba más o menos estabilizado en ciudades con una larga tradición griega, como las jonias, lo que explicaría que haya más información concreta interesante en ciudades de Licia o Cilicia, como la hubo en general en la época helenística. Por otra parte, tampoco podemos esperar que las artes y las letras estuvieran en boca de todos y protagonizaran los actos sociales de las ciudades. Si dentro de unos siglos intentan reconstruir nuestro

sos», ÖJh 62, 1993, pp. 105-111; V. Idil, «Die römischen Bibliotheken in Kleinasien: die Kelsusbibliothek in Ephesos und die Bibliothek in Nysa», en H. Friesinger-F. Krinzinger (edd.), 100 Jahre Österreichisches Forschung in Ephesos. Akten des Symposions Wien 1995, Viena, 1999.

${ }^{64}$ Heberdey, ÖJh 8, 1905, Bbl. 67. El testimonio de una donación privada para construir el pavimento del auditorium (juzgado) y de la biblioteca (3009) demuestra el interés de los ciudadanos en mantener el edificio. 
sistema educativo mediante telediarios o periódicos actuales, llegarían a la conclusión de que nuestra educación es fundamentalmente deportiva.

Mucho más difícil es la respuesta a cómo habría sido educado Habrócomes si hubiese sido hijo de un jornalero o alguien de profesión semejante. Es posible que para un niño de clase muy humilde el acceso a la educación sí fuese más difícil en este mundo grecorromano claramente elitista que en la alta edad helenística, pero en cualquier caso, los asuntos de las clases humildes, al menos en las grandes ciudades, no tenían cabida en las inscripciones públicas.

Aunque Habrócomes seguramente era demasiado pequeño o no había nacido aún, y aunque posiblemente acudir a una conferencia de Apolonio de Tiana no fuese necesariamente un síntoma de madurez intelectual, cuando éste tuvo la visión del asesinato de Domiciano en el 96 d.C. durante una charla en un $\gamma v \mu v \alpha ́ \sigma ı v$ de Éfeso, la ciudad se quedó estremecida, porque

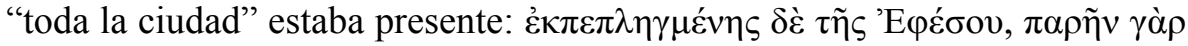

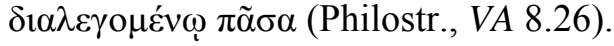

